\title{
RESEARCH COMMUNICATION \\ C8, a new member of the convertase family
}

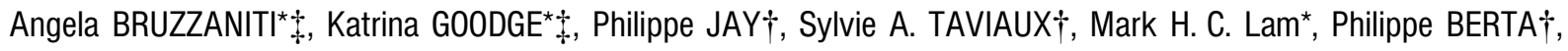 \\ T. John MARTIN*, Jane M. MOSELEY* and Matthew T. GILLESPIE* $§$ \\ *St. Vincent's Institute of Medical Research and The University of Melbourne, Department of Medicine, St. Vincent's Hospital, 41 Victoria Parade, Fitzroy, Vic. 3065, \\ Australia, and $\dagger$ Centre de Recherches de Biochimie Macromoleculaire, CNRS UPR9008, INSERM U.249, Route de Mende, 34033 Montpellier, France
}

\begin{abstract}
A novel subtilisin-like protein, PC8, was identified by PCR using degenerate primers to conserved amino acid residues in the catalytic region of members of the prohormone convertase family. PC8 was predicted to be 785 residues long and was structurally related to the mammalian convertases furin, PACE4, PC1 and PC2, sharing more than $50 \%$ amino acid identity over the catalytic region with these family members. PC8 possessed the catalytically important Asp, His, Asn and Ser amino acids, the homo B domain of this family of enzymes and a C-terminal hydrophobic sequence indicative of a transmembrane domain.
\end{abstract}

Structurally, PC8 is more related to furin and PACE4 than to PC1 or PC2. Like furin and PACE4, PC8 mRNA was found to be widely expressed; this is in contrast with $\mathrm{PC} 1$ and $\mathrm{PC} 2$, which have a restricted distribution. Two transcripts, of 4.5 and $3.5 \mathrm{~kb}$, were detected in both human cell lines and rat tissues. Unlike furin and PACE4, both of which map to chromosome 15, PC8 maps to chromosome 11q23-11q24, suggesting that this gene may have resulted from an ancient gene duplication event from either furin or PACE4, or conversely that these genes arose from PC8.

\section{INTRODUCTION}

Many biologically active proteins are synthesized as precursors which require specific endoproteolytic cleavage, commonly after dibasic residues, to generate their mature active forms. Over the last decade, a family of enzymes which is responsible for cleavage of pro-proteins to their biologically active forms has been identified [1-3]. This family of enzymes, known as 'prohormone convertases', are calcium-dependent serine proteinases exhibiting considerable sequence similarity to the bacterial subtilisins.

Kex2 was the first convertase to be described and was isolated and cloned from Saccharomyces cerevisiae [4,5]. Subsequently a further six members of this family, which exhibit highly conserved and similar catalytic domains, have been cloned from mammalian cells. These are furin [6,7], PC1 [8], also called 'PC3' [9], PACE4 $[10,11]$, also identified as 'PC7' [12], PC2 [8,13], PC4 [14,15] and PC5 [16,17] also known as PC6 [18].

Furin, PACE4 and PC5 are expressed in a variety of tissues and cell lines. However, there are differences in their relative abundance [7,10-12,17-19]. Whereas PC1 and PC2 have more restricted distribution and are predominant in the anterior and intermediate pituitary respectively [8,20-22], $\mathrm{PC} 4$ is restricted to the testis [14,15].

The consensus motif for precursor cleavage by furin is marked by an $\mathrm{R}-\mathrm{X}-\mathrm{K} / \mathrm{R}-\mathrm{R}$ sequence. However, furin has also been shown to cleave at $\mathrm{R}-\mathrm{X}-\mathrm{X}-\mathrm{R}$ and $\mathrm{R}-\mathrm{X}-\mathrm{X}-\mathrm{X}-\mathrm{K} / \mathrm{R}-\mathrm{R}$ sequences $[1-3,19,23]$. In contrast, $\mathrm{PC} 1$ and $\mathrm{PC} 2$ have been shown to direct precursor cleavage following dibasic amino acid pairs [20,24]; PC1 can also cleave at mono-arginyl sites with basic residues at the -4 or -6 position [25]. These sites are found in many propeptides and polypeptide precursors, and the mammalian pro- hormone convertases have been found to cleave a number of these, including pro-opiomelanocortin [24], proinsulin [26], proinsulin receptor [27], prorelaxin [28], proalbumin [29], pro-(von Willebrand factor) [19] and pro-( $\beta$-nerve growth factor) [23].

In the course of studies aimed at understanding the posttranslational processing of parathyroid hormone-related protein, which elicits multiple biological actions and contains a number of potential sites for convertase action, including two furin target sequences [30,31], we have identified a new member of the convertase family. Reported here is the identification, tissue distribution and chromosomal assignment of this new convertase which we have designated 'PC8'.

\section{MATERIALS AND METHODS}

\section{Cell culture}

The human squamous cancer cell lines BEN, COLO 16 and the spontaeously immortalized human keratinocyte cell line $\mathrm{HaCaT}$ were cultured as previously described [31-33].

\section{PCR oligonucleotides}

oPC8 \{5'-GGGCCCCA(G/A)CTNGC(G/A)CT(G/A)TA-3', antisense strand oligonucleotide to amino acids $250-256$ of human furin [7] $\}$, oPC10 $\left\{5^{\prime}-\mathrm{TANCC}(\mathrm{A} / \mathrm{G}) \mathrm{TC}(\mathrm{A} / \mathrm{G}) \mathrm{CA}(\mathrm{A} /\right.$ $\mathrm{G}) \mathrm{T}(\mathrm{C} / \mathrm{T})(\mathrm{A} / \mathrm{G}) \mathrm{CA}-3^{\prime}$, antisense strand oligonucleotide to amino acids 303-308 of human furin [7] $\}$, oPC12 $\left\{5^{\prime}-\right.$ TGCTGCAT(A/G)TCNCGCCA-3', antisense strand oligonucleotide to amino acids 390-395 of human furin [7]\}, oPC13

Abbreviations used: RT, reverse transcription (or transcribed); GAPDH, glyceraldehyde-3-phosphate dehydrogenase; UTR, untranslated region; PTHrP, parathyroid-hormone-related protein.

* These authors contributed equally to this work.

$\S$ To whom correspondence should be addressed. 
$\left\{5^{\prime}-\mathrm{CA}(\mathrm{T} / \mathrm{C}) \mathrm{GG}(\mathrm{A} / \mathrm{C}) \mathrm{AC}(\mathrm{A} / \mathrm{T})(\mathrm{A} / \mathrm{C}) \mathrm{G}(\mathrm{A} / \mathrm{C} / \mathrm{G}) \mathrm{TGTGC}-\right.$ (A/C/T)GG-3', sense strand oligonucleotide to amino acids 194-200 of human furin [7]\}, oPC33 [5'-CAACAACAGCTTCTGTGC-3', sense strand oligonucleotide to nucleotides 740-758 of human PC8 (Figure 1)], oPC34 [5'-TACCCGGATACCTGCGAT-3', antisense strand oligonucleotide to nucleotides 784-801 of human PC8 (Figure 1)], oPC35 [5'-TGATCTGATAGTGCTTGT-3', antisense strand oligonucleotide to nucleotides $845-861$ of human PC8 9 (Figure 1)], T7 (5'-AATACGACTCACTATAG-3'), GAPDH-1, GAPDH-3, GAPDH-4 and GAPDH-5 have been described previously $[33,34]$.

\section{Northern-blot analysis and reverse transcription PCR (RT-PCR)}

Total RNA was extracted using guanidinium chloride as described [35] and polyadenylated RNA was recovered from total RNA using a QuickPrep Micro mRNA purification kit (Pharmacia Biotech Inc., Uppsala, Sweden). Northern analysis and hybridizations were performed as previously reported [33]. Specifically bound probe was quantified by phosphorImager analysis (Molecular Dynamics, Sunnyvale, CA, U.S.A.).

RT-PCR was performed on $5 \mu \mathrm{g}$ total RNA isolated from cells or tissues as previously described [33,34]. PCR cycling conditions were: $94{ }^{\circ} \mathrm{C}$ for $30 \mathrm{~s}, 45-55^{\circ} \mathrm{C}$ for $60 \mathrm{~s}$ (depending on the oligonucleotide combinations), $72{ }^{\circ} \mathrm{C}$ for $30 \mathrm{~s}$ to $2 \mathrm{~min}$, for 40 cycles followed by $10 \mathrm{~min}$ elongation time at $72{ }^{\circ} \mathrm{C}$. PCR products resolved on a $2 \%(\mathrm{w} / \mathrm{v})$-agarose gel were subsequently extracted using Qiaex DNA purification kit (Qiagen Inc., Chatsworth, CA, U.S.A.) or Wizard PCR Preps (Promega Corp., Madison, WI, U.S.A.) and PCR products were cloned into pCRScript II (Stratagene, La Jolla, CA, U.S.A.) or pGEMT (Pharmacia Biotech Inc.). DNA sequence analysis from both strands was performed using Sequenase sequencing (USB, Cleveland, $\mathrm{OH}$, U.S.A.). Sequences were then compared with sequences in the

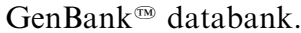

\section{Chromosomal localization}

Metaphases were obtained from phytohaemagglutininstimulated lymphocytes from a healthy donor after thymidine synchronization and bromodeoxyuridine incorporation. The fulllength cDNA HE6WCR40 was labelled with biotinyl-16-dUTP by random priming. Fluorescence in situ hybridization was performed as previously described [37].

\section{RESULTS AND DISCUSSION}

In order to identify convertase family members which may be involved in post-translational processing of parathyroid-hormone-related protein (PTHrP), we characterized PTHrP-producing cells for their convertase mRNA complement. Degenerate oligonucleotide primers (oPC2, oPC8, oPC10, oPC12 and oPC13) were designed to amino acid residues conserved between the catalytic regions of furin, $\mathrm{PC} 1$ and $\mathrm{PC} 2$. These primers, when used in RT-PCR, would allow the identification of known convertases and potentially new members of the convertase family. Total RNA from BEN cells was reverse-transcribed with random hexamers, and 30 cycles of PCR undertaken with the primers oPC8 and oPC13. Resultant PCR fragments of approx. $190 \mathrm{bp}$ were subcloned into pCRScript and sequenced. By this approach, 18 clones showing sequence similarity to furin, two to PACE4 and two to PC2, were recovered. In addition, another clone, $\mathrm{BC} 20$, of $187 \mathrm{bp}$ was detected, and this was highly related to, but distinct from, the other convertase cDNA clones.
The cDNA sequence of $\mathrm{BC} 20$ was extended over the catalytic domain by RT-PCR with a BC20-specific sense-strand oligonucleotide, oPC33, and antisense-strand degenerate primers (oPC10 and oPC12) to conserved amino acids in the catalytic domain between furin, $\mathrm{PC} 1$ and $\mathrm{PC} 2$, which resulted in fragments 343 and $617 \mathrm{bp}$ respectively; the sequences of these fragments have been previously reported $[38,39]$. It was clear that $\mathrm{BC} 20$ formed a new member of the mammalian prohormone convertase family and we refer to it now as 'PC8', adopting the nomenclature of Seidah et al. [8]. 5' Sequences were amplified by anchored PCR from a human liver cDNA library in pcDNAIneo (Stratagene) using the PC8-specific antisense oligonucleotide (oPC34) and a sense-strand-specific primer to the T7 RNA polymerase promoter. Combined, these strategies yielded overlapping sequences from the $5^{\prime}$ untranslated regions (UTR) to the end of the catalytic domain of PC8 (Figure 1, nucleotides 1-1320). During database searches a cDNA clone, HE6WCR40 (GenBank ${ }^{\text {(ix }}$ accession no. H58761), representing an N-terminally truncated PC8 cDNA, was identified. This clone provided confirmation of the sequence obtained by RT-PCR and the complete $3^{\prime}$ coding region of PC8. Subsequently, the entire coding region of PC8 (GenBank ${ }^{\text {(in }}$ accession no. U40623) was amplified from BEN cell RNA by RT-PCR and the sequence was identical with that determined for HE6WCR40. The cDNA clones predicted PC8 to be encoded by a mRNA species of $3.3 \mathrm{~kb}$, composed of a $21 \mathrm{bp} \mathrm{5}$ UTR, an open reading frame of $2355 \mathrm{bp}$ coding for a protein of 785 amino acids and a 3' UTR of 925 nucleotides. The 3' UTR contained a polyadenylation signal, AATAAA, which was followed 12 nucleotides later by a poly(A) stretch (not shown). The primary protein sequence predicts a 42 -residue signal peptide at the $\mathrm{N}$-terminus, six potential $\mathrm{N}$-linked glycosylation sites (residues 167, 175, 200, 241, 511 and 763) and a 22-amino-acid transmembrane region between residues 666 and 687 (Figure 1). The Met residue at position 36 is within a consensus Kozak sequence [40]. However, if this was the initiating AUG codon, the protein would lack a signal peptide. The N-terminus of mature PC8 is assumed to begin at Ser-142, following the sequence R-A-K-R, which fits the $\mathrm{R}-\mathrm{X}-\mathrm{K} / \mathrm{R}-\mathrm{R}$ consensus motif cleavage site for furin. While this manuscript was in preparation, a cDNA clone, HSU33849, identical with PC8 (except for a 131-nucleotide extension of the 5' UTR and the last nucleotide of HSU33849 corresponding to nucleotide 2559 in Figure 1) and a partial cDNA clone, 45900, sharing structural similarity with PC8, were deposited in the GenBank $^{(m)}$ database (accession nos. U33849 and H09374 respectively).

The chromosomal location of the PC8 gene was determined by in situ hybridization using the HE6WCR40 cDNA clone. A total of 30 metaphase preparations were analysed, and a specific labelling of bands 11q23-q24 was observed on four (seven cells), three (four cells), two (12 cells) and one (four cells) chromatid of the chromosome homologues (Figure 2). In total, 27 nonspecific hybridizations were scattered throughout the other chromosomes, and no secondary peak was detected.

\section{Comparison of PC8 with other mammalian convertases}

An amino acid alignment of PC8 to the known human convertases furin, PACE4, PC1 and PC2 is given in Figure 3. Each possesses a signal peptide, an $\mathrm{N}$-terminal domain, a catalytic domain, a homo B domain and a C-terminal domain. PC8 shares its highest identity with furin (54\%), PACE4 (53\%), PC1 (53\%) and PC2 $(52 \%)$ within the 289 amino acid catalytic domain. In addition, PC8 possesses the conserved amino acids Asp (197), His (228), Asn (329; Asp in PC2) and Ser (406), which are catalytically important. Outside the catalytic domain, the con- 


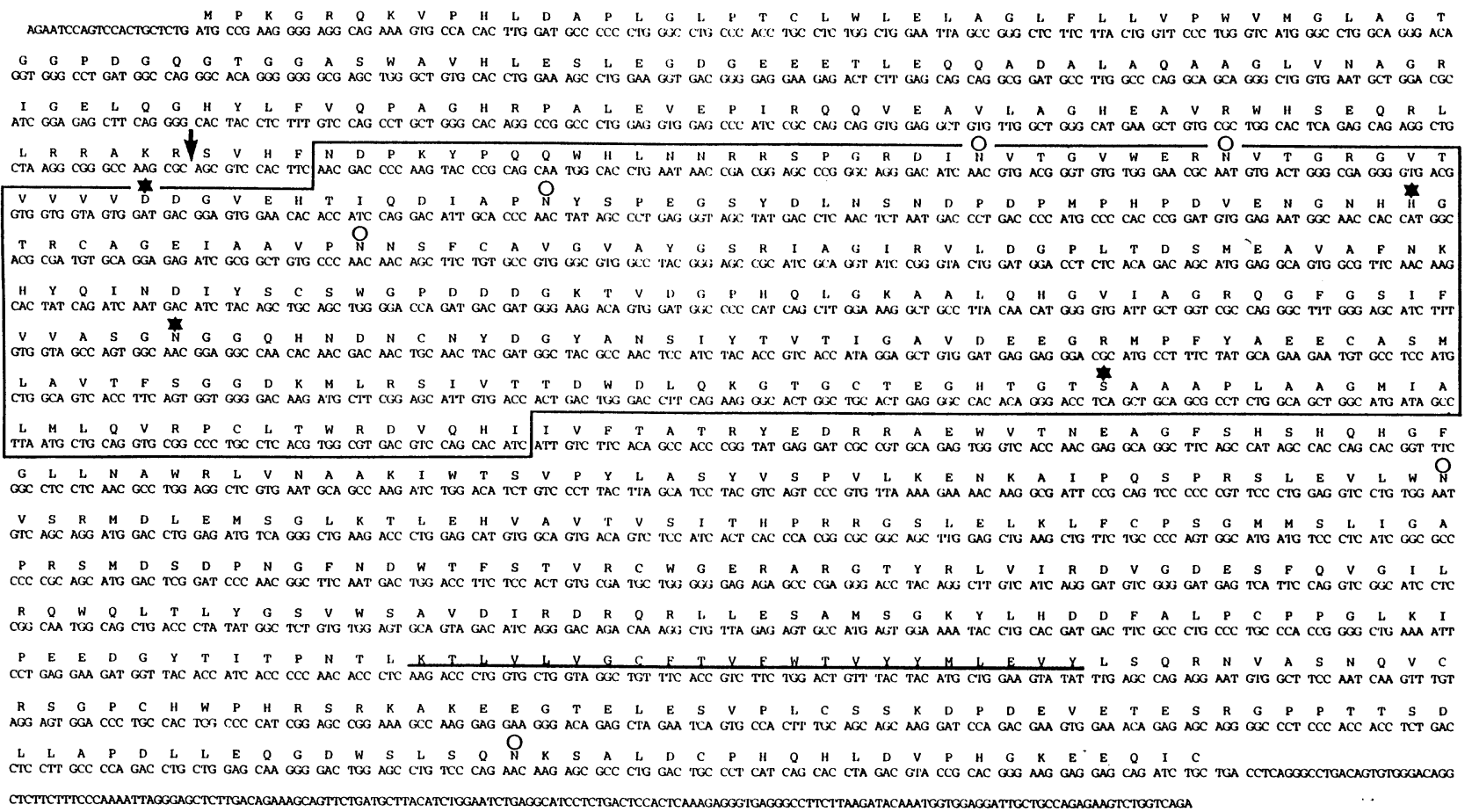

\section{Figure 1 Nucleotide and predicted amino acid sequences of PC8}

The putative cleavage site to release the mature protein from the propeptide is indicated by the arrow $(\downarrow)$, and the putative transmembrane region is underlined. The subtilisin-like catalytic domain is boxed, and the catalytically important Asp, His, Asn, and Ser residues are indicated by $\$$. Consensus sites for Asn-linked glycosylation are marked by the open circles $(\bigcirc)$.

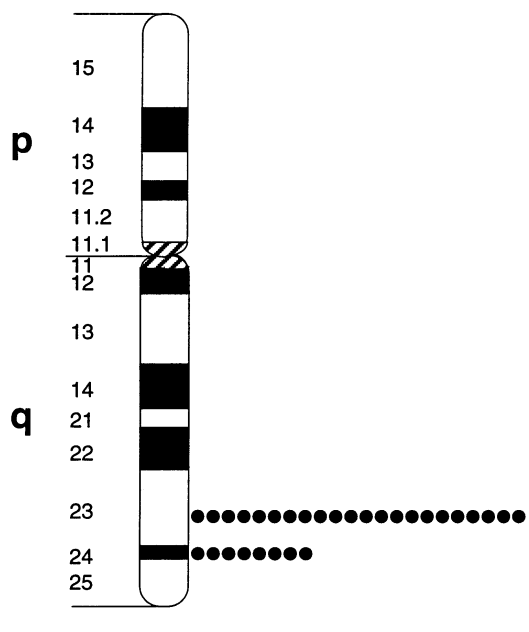

11

\section{Figure 2 Idiogram of chromosome 11}

Idiogram of the chromosome 11 homologue showing the unequivocal distribution of fluorescent spots on the 11q23-q24 bands for 15 metaphases.

served amino acid identity between PC8 and other convertases is dramatically reduced. From the initiating Met to the catalytic region (145 amino acids), PC8 shares $17 \%$ identity with furin, $18 \%$ with PACE4 and PC1 and $11 \%$ with PC2. Within this region, the $\mathrm{R}-\mathrm{X}-\mathrm{K} / \mathrm{R}-\mathrm{R}$ consensus motif ( $\mathrm{PC} 8$ residues 138-141) for precursor cleavage catalysed by furin is conserved with other members of the prohormone convertase family (Figure 3). Sequences C-terminal to the catalytic domain (351 amino acids), which encompass the homo $\mathrm{B}$ domain, were marginally more conserved than those of the N-terminus: $24 \%$ identity with PACE4, $20 \%$ with furin and PC1 and $16 \%$ with PC2. PC8 contains five Cys residues (232, 245, 337, 367 and 398), which are conserved with furin, PACE4, PC1 and PC2; the conservation of these residues indicates that they may be involved in disulphide bridges. The C-terminal Cys residue is only shared with furin and PACE4. However, PC8 does not contain a Cys-rich region like furin or PACE4. Only one of the six potential N-linked glycosylation sites of PC8 (Asn-241) was conserved with another family member (PACE4, Asn-199).

Unlike furin, PACE4, PC1 and PC2, PC8 does not contain an RGD sequence, which is a receptor recognition signal of extracellular-matrix proteins, but contains an RGS sequence (residues 539-541) at the position corresponding to the RGD motif in the other convertases.

\section{Expression of PC8 mRNA}

PC8 mRNA transcripts of 3.5 and $4.5 \mathrm{~kb}$ were found to be expressed in human cell lines (Figure 4A) and in all rat tissues examined (results not shown); these cell lines and tissues were also found to express mRNA for furin and PACE4 (results not shown). The $4.5 \mathrm{~kb}$ transcript may result from either alternative mRNA splicing, alternate promoter usage or use of a different polyadenylation motif. For confirmation of the Northern blots, RT-PCR was performed with the PC8-specific primers oPC33 


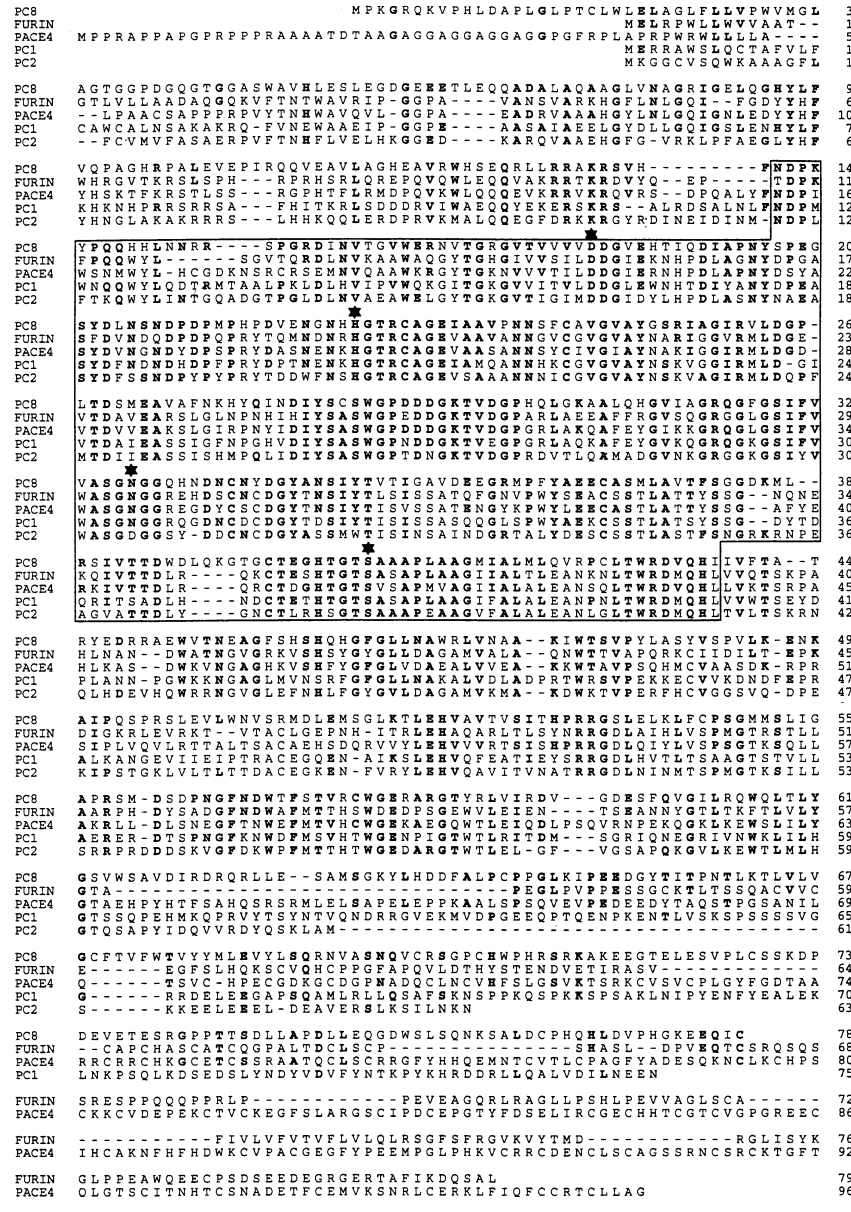

Figure 3 Complete amino acid sequence predicted for PC8 aligned to furin, PACE4, PC1 and PC2

The subtilisin-like catalytic domains are boxed and the catalytically important Asp, His, Asn (Asp), and Ser residues are indicated by $\star$. Residues of identity with PC8 are indicated in bold, with gaps introduced to maximize the alignments. Residue numbers are indicated at right.

and oPC35 under saturating PCR conditions, and resultant products were verified by hybridization analysis with an internal oligonucleotide, oPC34 (Figure 4B). All tissues were found to express PC8 mRNA. The ability of the primer pairs to specifically amplify PC8 mRNA from human and rat cDNA suggests that the sequences are well conserved between the two species; the primers did not amplify cDNA for PC1, PC2, PACE4 or furin from either species (results not shown). Since PC8 is widely expressed in endocrine and non-endocrine tissues, it is likely that PC8 is an enzyme of the constitutive pathway of protein secretion and is unlike PC1 and PC2 which are involved in the regulated pathway and have a distribution restricted to endocrine and neuroendocrine cells.

From a comparative perspective, PC8 shares more features in common with furin and PACE4 than with PC1 and PC2. These include: (i) high amino acid identity over the entire molecule with furin and PACE4, whilst the similarity to PC1 and PC2 is lower; (ii) like furin and PACE4, PC8 contains a long (42-amino-acid) signal peptide, whereas the signal sequences of $\mathrm{PC} 1$ and $\mathrm{PC} 2$ are relatively short; (iii) in common with furin, PC8 possesses a putative transmembrane domain, suggesting that it may be localized to the Golgi; and (iv) the mRNA for PC8 is ubiquitously expressed like those for furin and PACE4, which is in marked

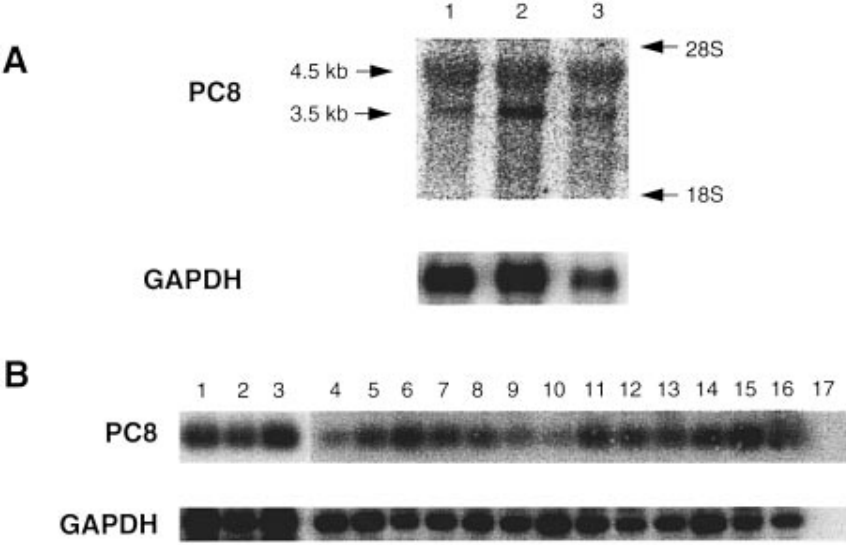

Figure 4 Expression of PC8 in human cell lines and adult rat tissues

(A) A $5 \mu$ g portion of polyadenylated RNA from cell lines were electrophoresed through $1.2 \%$ agarose/formaldehyde gels, transferred to nylon and hybridized with ${ }^{32} \mathrm{P}$-labelled HE6WCR40 (PC8). The blots were reprobed with a cDNA for glyceraldehyde-3-phosphate dehydrogenase (GAPDH) as an indicator of RNA loading. Lanes contain polyadenylated RNA isolated from human cell lines: 1, BEN; 2, COLO 16; 3, HaCaT. The positions of the $4.5 \mathrm{~kb}$ and the $3.5 \mathrm{~kb}$ mRNA species are indicated on the left. (B) RT-PCR analysis of PC8 mRNA was conducted under saturating PCR conditions using the PC8-specific primers $\mathrm{OPC} 33$ and $\mathrm{OPC} 35$, which amplify a 121 bp fragment of PC8. Lanes contain RT-PCR products from total RNA isolated from the human cell lines (1, BEN; 2, COL0 16;3, HaCaT) and from rat tissues (4, brain; 5 , thymus; 6. skin; 7, lung; 8, kidney; 9, spleen; 10, liver; 11, stomach; 12, bladder; 13, heart; 14 , skeletal muscle; 15 , ovary; 16, testis). Lane 17 is a PCR negative control lane in which the RNA subjected to PCR had not been reverse-transcribed. Products were verified with a ${ }^{32} \mathrm{P}$ labelled internal PC8-specific oligonucleotide, OPC34. Amplification of a $415 \mathrm{bp}$ fragment of GAPDH cDNA was achieved with GAPDH-specific primers GAPDH-3 and GAPDH-4 (human) or GAPDH-5 and GAPDH-4 (rat), and products were verified with the internal detection oligonucleotide GAPDH-1 [33,34].

contrast with the mRNAs for $\mathrm{PC} 1$ and $\mathrm{PC} 2$, which are restricted to endocrine and neuroendocrine cells. Combined, these data suggest that PC8 is more closely related to furin and PACE4 than to PC1 and PC2. As such, PC8, furin and PACE4 may have been derived from a common ancestral gene which has been duplicated on chromosome 15 for furin and PACE4 and on chromosome 11 for PC8. It remains to be established whether PC8 can fulfill the functions of furin, whether it does indeed act as a constitutive pathway enzyme and whether it has asubstrate sequence specificity for cleavage of proteins similar to that of furin or other members of the convertase family.

This work was supported by a Program Grant from the National Health and Medical Research Council of Australia, by a grant from Chugai Pharmaceutical Co., Ltd., Japan, to T. J. M., J. M. M. and M. T.G., and by Grant GREG 43 to P. B. We are grateful to Dr. D. Stapleton for his helpful discussions.

\section{REFERENCES}

1 Barr, P. (1991) Cell 66, 1-3

2 Seidah, N. and Chrétien, M. (1992) Trends Endocrinol. Metab. 3, 133-140

3 Steiner, D. F., Smeekens, S. P., Ohagi S. and Chan, S. J. (1992) J. Biol. Chem. 267, 23435-23438

4 Julius, D., Brake, A., Blair, L., Kunisawa, R. and Thorner, J. (1984) Cell 37 1075-1089

5 Fuller, R. S., Brake, A. and Thorner, J. (1989) Proc. Natl. Acad. Sci. U.S.A. 86, 1434-1438

6 Roebroek, A. J. M., Schalken, J. A., Leunissen, J. A. M., Onnekink, C., Bloemers, H. P. J. and Van de Ven, W. J. M. (1986) EMBO J. 5, 2197-2202

7 van den Ouweland, A. M. W., van Duijnhoven, H. L. P., Keizer, G. D., Dorssers, C. J. and Van de Ven, W. J. M. (1990) Nucleic Acids Res. 18, 664

8 Seidah, N. G., Gaspar, L., Mion, P., Marcinkiewicz, M., Mbikay, M. and Chrétien, M. (1990) DNA Cell Biol. 9, 415-424 
9 Smeekens, S. P., Avruch, A. S., LaMendola, J., Chan, S. J. and Steiner, D. F. (1991) Proc. Natl. Acad. Sci. U.S.A. 88, 340-344

10 Kiefer, M. C., Tucker, J. E., Joh, R., Landsberg, K. E., Saltman, D. and Barr, P. J. (1991) DNA Cell Biol. 10, 757-769

11 Johnson, R. C., Darlington, D. N., Hand, T. A., Bloomquist, B. T. and Mains, R. E. (1994) Endocrinology (Baltimore) 135, 1178-1185

12 Tsuji, A., Hine, C., Mori, K., Tamai, Y., Higashine, K., Nagamune, H. and Matsuda, Y. (1994) Biochem. Biophys. Res. Commun. 202, 1452-1459

13 Smeekens, S. P. and Steiner, D. F. (1990) J. Biol. Chem. 265, 2997-3000

14 Nakayama, K., Kim, W. S., Torii, S., Hosaka, M., Nakagawa, T., Ikemizu, J., Baba, T. and Murakami, K. (1992) J. Biol. Chem. 267, 5897-5900

15 Seidah, N. G., Day, R., Hamelin, J., Gaspar, A., Collard, M. W. and Chrétien, M. (1992) Mol. Endocrinol. 6, 1559-1570

16 Seidah, N. G., Day, R., Marcinkiewicz, M., Benjannet, S. and Chrétien M. (1991) Enzyme 45, 271-284

17 Lusson, J., Vieau, D., Hamelin, J., Day, R., Chrétien, M. and Seidah, N. G. (1993) Proc. Natl. Acad. Sci. U.S.A. 90, 6691-6695

18 Nakagawa, T., Hosaka, M., Torii, S., Watanabe, T., Murakami, K. and Nakayama, K. (1993) J. Biochem (Tokyo). 113, 132-135

19 Wise, R. J., Barr, P. J., Wong, P. A., Kiefer, M. C., Brake, A. J. and Kaufman, R. J. (1990) Proc. Natl. Acad. Sci. U.S.A. 87, 9378-9383

20 Seidah, N. G., Marcinkiewicz, M., Benjannet, S., Gaspar, L., Beaubien, G., Mattei, M. G., Lazure, C., Mbikay, M. and Chrétien, M. (1991) Mol. Endocrinol. 5, 111-122

21 Joshi, D., Miller, M. M., Seidah, N. G. and Day, R. (1995) Endocrinology (Baltimore) 136, 2721-2729

22 Scopsi, L., Gullo, M., Rilke, F., Martin, S. and Steiner, D. F. (1995) J. Clin. Endocrinol. Metab. 80, 294-301

23 Bresnahan, P. A., Leduc, R., Thomas, L., Thorner, J., Gibson, H. L., Brake, A. J. and Thomas, G. (1990) J. Cell. Biol. 111, 2851-2859

24 Benjannet, S., Rondeau, N., Day, R., Chretien, M. and Seidah, N. G. (1991) Proc. Natl. Acad. Sci. U.S.A. 88, 3564-3568
25 Nakayama, K., Watanabe, T., Nakagawa, T., Kim, W.-S., Nagahama, M., Hosaka, M., Hatsuzawa, K., Kondoh-Hashiba, K. and Murakami, K. (1992) J. Biol. Chem. 267 16335-16340

26 Bennet, D. L., Bailyes, E. M., Nielsen, E., Guest, P. C., Rutherford, N. G., Arden, S.D. and Hutton, J. C. (1992) J. Biol. Chem. 267, 15229-15236

27 Bravo, D. A., Gleason, J. B., Sanchez, R. I., Roth, R. A. and Fuller, R. S. (1994) J. Biol. Chem. 269, 25830-25837

28 Marriott, D., Gillece-Castro, B. and Gorman, C. M. (1992) Mol. Endocrinol. 6 $1441-1450$

29 Brennan, S. 0. and Nakayama, K. (1994) FEBS Lett. 338, 147-152

30 Diefenbach-Jagger, H., Brenner, C., Kemp, B. E., Baron, W., McLean, J., Martin, T. J. and Moseley, J. M. (1995) Eur. J. Biochem. 229, 91-98

31 Moseley, J. M. and Gillespie, M. T. (1995) Crit. Rev. Clin. Lab. Sciences 32 299-343

32 Suva, L. J., Winslow, G. A., Wettenhall, R. E. H., Hammonds, R. G., Moseley, J. M., Diefenbach-Jagger, H., Rodda, C. P., Kemp, B. E., Rodriguez, H., Chen, E. Y., Hudson, P. J., Martin, T. J. and Wood, W. I. (1989) Science 237, 893-896

33 Glatz, J. A., Heath, J. K., Southby, J., O'Keeffe, L. M., Kiriyama, T., Moseley, J. M., Martin, T. J. and Gillespie, M. T. (1994) Mol. Cell. Endocrinol. 101, 295-306

34 Heath, J. K., Southby, J., Fukumoto, S., O'Keeffe, L. M., Martin, T. J. and Gillespie, M. T. (1995) Biochem. J. 307, 159-167

35 Traianedes, K., Findlay, D. M., Martin, T. J. and Gillespie, M. T. (1995) J Biol. Chem. 270, 20891-20894

36 Chomcznski, P. and Sacchi, N. (1987) Anal. Biochem. 162, 156-159

37 Taviaux, S. A. and Demaille, J. G. (1993) Genomics 15, 194-196

38 Bruzzaniti, A., Goodge, K., Martin, T. J., Moseley, J. M. and Gillespie, M. T. (1995) Bone 16 (suppl. 1), 126S \#165

39 Gillespie, M. T., Bruzzaniti, A., Goodge, K., Moseley, J. M. and Martin, T. J. (1995) J. Cell. Biochem. 19B, 243 \#B7-102

40 Kozak, M. (1986) Cell 44, 283-292

Received 11 December 1995/11 January 1996; accepted 11 January 1996 